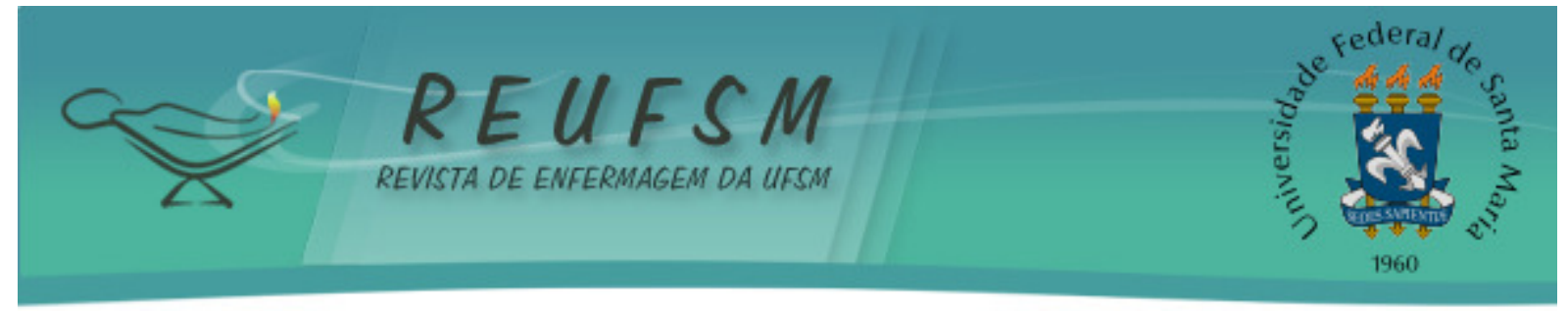

ARTIGO ORIGINAL

\title{
AMAMENTAÇÃO: A INFLUÊNCIA FAMILIAR E O PAPEL DOS PROFISSIONAIS DE SAÚDE
}

\begin{abstract}
BREASTFEEDING: THE FAMILY INFLUENCE AND THE ROLE OF HEALTH PROFESSIONALS
\end{abstract}
LACTANCIA: LA INFLUENCIA FAMILIAR Y EL PAPEL DE LOS PROFESIONALES DE SALUD

Lisie Alende Prates ${ }^{1}$

Joice Moreira Schmalfuss ${ }^{2}$

Jussara Mendes Lipinski ${ }^{3}$

\section{Doi: $10.5902 / 2179769210631$}

RESUMO: Objetivo: conhecer a influência familiar na amamentação e refletir sobre o papel dos profissionais de saúde nessa prática. Método: pesquisa qualitativa descritiva, utilizando pressupostos da pesquisa participante, com 21 puérperas em aleitamento materno exclusivo ou complementar. Os dados foram coletados por meio de entrevista e analisados pela análise de conteúdo do tipo temática. Resultados: as experiências da mulher e de pessoas ligadas à mesma exercem forte influência no ato de amamentar. A prática efetiva da amamentação envolve o (re)aprendizado da mulher e o apoio da família e dos profissionais de saúde. Considerações finais: os profissionais de saúde devem aproximar a família das ações que envolvem a amamentação, de modo a conhecer os saberes e experiências que permeiam esta prática e implementar ações que possam promovê-la, protegê-la e apoiá-la.

Descritores: Aleitamento materno; Família; Pessoal de saúde; Enfermagem.

ABSTRACT: Aim: to know the family influence on breastfeeding and reflect on the role of health professionals in this practice. Method: descriptive qualitative research, using assumptions of participatory research, with 21 postpartum women exclusive breastfeeding or complementary. Data were collected through interviews and analyzed by analysis of thematic content. Results: the experiences of women and people connected to the same wield have a strong influence in the act of breastfeeding. The effective practice of breastfeeding involves the (re)learning of the woman and the support of family and health professionals. Final considerations: health professionals should to approximate the family of actions that involve breastfeeding, in order to meet the knowledge and experiences that permeate this practice and to implement actions that can promote it, protect it and support it.

Descriptors: Breastfeeding; Family; Health personnel; Nursing.

RESUMEN: Objetivo: conocer la influencia familiar en la lactacia materna y reflexionar sobre el papel de los profesionales de salud en esta práctica. Método: investigación cualitativa descriptiva, basada en la investigación participante, con 21 madres recientes en lactancia materna exclusiva o complementar. Los datos fueron recolectados a través de

\footnotetext{
${ }^{1}$ Enfermeira. Mestranda em Enfermagem pelo Programa de Programa de Pós-Graduação em Enfermagem (PPGEnf) da Universidade Federal de Santa Maria (UFSM). Santa Maria, Rio Grande do Sul (RS), Brasil. E-mail: lisiealende@hotmail.com

${ }^{2}$ Enfermeira. Mestre em Enfermagem pelo PPGEnf da Universidade Federal do Rio Grande do Sul (UFRGS). Especialista em Enfermagem Obstétrica pela Universidade do Vale do Rio dos Sinos (UNISINOS). Professora Assistente da Universidade Federal da Fronteira Sul (UFFS) - Campus Chapecó/Santa Catarina (SC) e docente do Curso de Especialização em Enfermagem na Saúde da Mulher da Universidade Federal do Pampa (UNIPAMPA). Chapecó, SC, Brasil. E-mail: joicemschmalfuss@gmail.com

${ }^{3}$ Enfermeira. Doutora em Enfermagem pelo PPGEnf da UFRGS. Professora Adjunta da UNIPAMPA e docente do Curso de Especialização em Enfermagem na Saúde da Mulher da UNIPAMPA. Uruguaiana, RS, Brasil. E-mail: jussaralipinski@gmail.com
} 


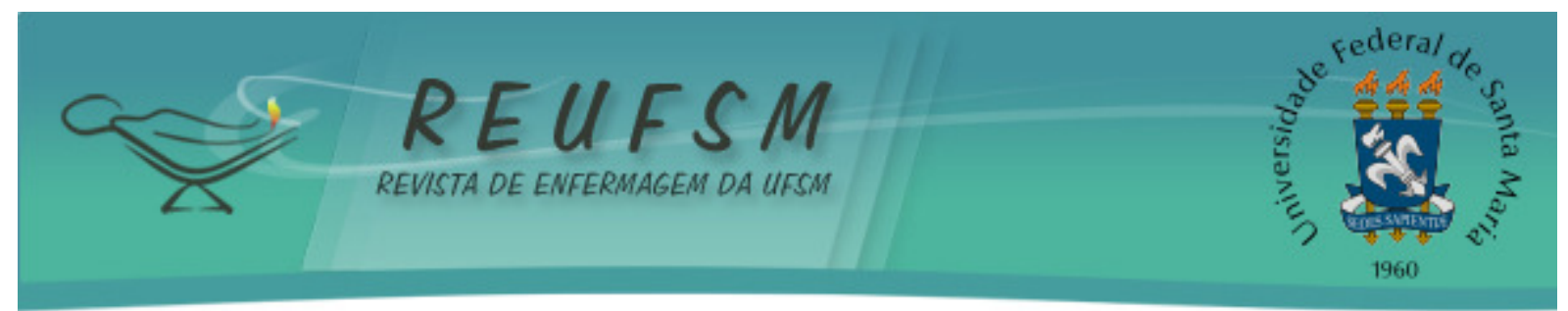

entrevistas y analizados mediante análisis de contenido temático. Resultados: las experiencias de las mujeres y personas vinculadas a las mismas ejercen fuerte influencia en el acto de la lactancia materna. La práctica efectiva de la lactancia materna implica la (re)aprendizaje de la mujer y el apoyo famíliar y de los profesionales de salud. Consideraciones finales: los profesionales de salud deben acercar la família a las acciones que implican la lactancia, para introducir los conocimientos y experiencias que atraviesan esta práctica y poner en marcha acciones que pueden promoverla, protegerla y apoyarla.

Descriptores: Lactancia materna; Familia; Personal de salud; Enfermería.

\section{INTRODUÇÃO}

A família representa a rede social primária de todo e qualquer indivíduo. É um sistema de relações contínuas e interligadas, estabelecida por meio de uma rede de parentesco, inserida em um determinado contexto sociocultural. ${ }^{1}$ A família possui a capacidade de atuar como uma unidade de cuidado e suporte de seus membros, devido, especialmente, a sua forma própria de cuidar pautada em valores, crenças e conhecimentos. ${ }^{1-2}$

$\mathrm{Na}$ prática profissional em saúde, tem-se verificado a importância da família, principalmente, durante o puerpério, nas questões ligadas ao aconselhamento, apoio e cuidado à mulher e ao recém-nascido, assim como na amamentação.

A amamentação representa a oferta de leite materno diretamente na mama da mulher e difere de aleitamento materno, o qual envolve todas as formas do lactente receber o leite materno, seja na mama ou ordenhado, e pode ainda ser classificado em exclusivo, predominante, complementado e misto ou parcial. ${ }^{3}$

Por se tratar de um processo histórico, social, cultural e psicologicamente delineado, a amamentação sempre foi muito ligada às crenças, valores e mitos repassados de forma intergeracional na rede familiar. ${ }^{4}$ Desse modo, percebe-se a família como o pilar fundamental para ações de promoção e incentivo ao aleitamento materno, já que as experiências da mesma são muito valorizadas e respeitadas, especialmente nos cuidados com o recém-nascido. ${ }^{5-6}$

Embora se reconheça que a família exerce papel fundamental no sucesso da amamentação, muitos profissionais de saúde costumam desconsiderar as experiências dos familiares, sem vislumbrar as potencialidades destes na adesão e manutenção da amamentação. ${ }^{4}$

Desta forma, conhecer e compreender as experiências em amamentação, no âmbito familiar, possibilitaria a reflexão dos profissionais de saúde quanto à necessidade de novas estratégias na construção de suas ações e consequente análise, com tomada de decisão do que pode ser feito para minimizar e/ou reduzir a interrupção precoce dessa prática.

Considerando o misto de natureza e cultura que envolve a amamentação, as ações, individuais e coletivas, devem ser planejadas, contemplando tanto os saberes técnicos quanto os saberes populares, bem como as questões subjetivas da mulher. ${ }^{7}$

Diante do exposto, a presente pesquisa teve como questão norteadora: qual a influência da rede familiar na prática da amamentação? Para responder a este questionamento, o objetivo deste artigo foi conhecer a influência familiar na amamentação e refletir sobre o papel dos profissionais de saúde nessa prática. 


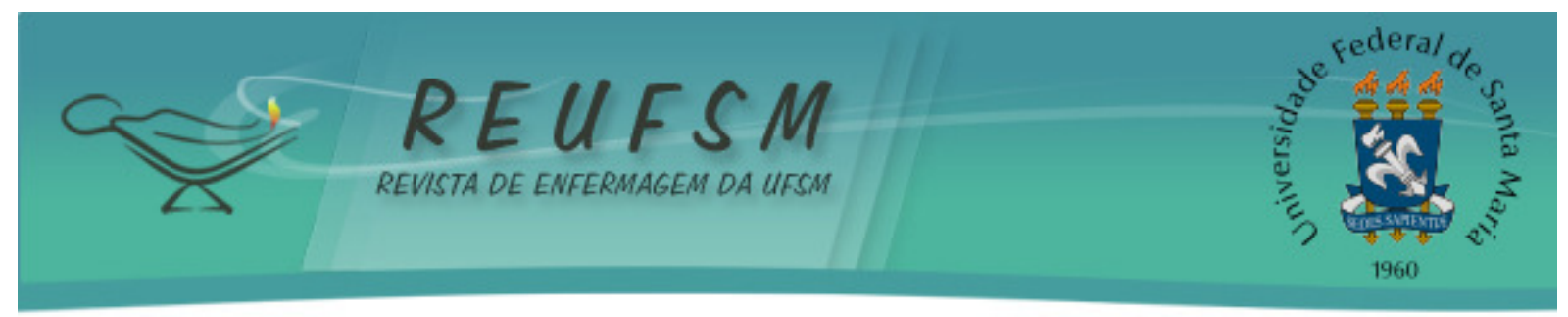

MÉTODO

Trata-se de uma pesquisa descritiva, com abordagem qualitativa, utilizando pressupostos da pesquisa participante. Foram sujeitos do estudo 21 puérperas, sendo que a participação das mesmas na pesquisa se deu, inicialmente, por contato a partir da primeira consulta de pré-natal realizada em uma Unidade Básica de Saúde do município de Uruguaiana-Rio Grande do Sul.

Foram incluídas puérperas em aleitamento materno exclusivo ou complementar e maiores de 18 anos. O número de participantes foi definido por meio do critério de saturação dos dados. ${ }^{8}$

A coleta de dados foi realizada de abril a setembro de 2012, nos domicílios das puérperas, por meio de entrevistas com duração média de 30 minutos, compostas por questões abertas referentes à temática em estudo. A análise dos dados foi fundamentada na análise de conteúdo do tipo temática. ${ }^{8}$

Com vistas a garantir a homogeneidade da coleta de dados, as entrevistas não foram gravadas, visto que desde o contato inicial com as participantes houve recusa quanto à realização da gravação e, portanto, optou-se pela transcrição das respostas.

0 estudo respeitou todos os preceitos éticos, ${ }^{9}$ sendo que a coleta dos dados foi iniciada somente após a aprovação do projeto pelo Comitê de Ética em Pesquisa (CEP) da Universidade Federal do Pampa (UNIPAMPA), sob o número de registro UNIPAMPA/CEP 030.2011, em agosto de 2011. Também foi solicitada a autorização das participantes por meio da assinatura do Termo de Consentimento Livre e Esclarecido (TCLE). Para preservar o anonimato das mulheres entrevistadas estas foram identificadas pela letra "E" $e$ números, respeitando a sequência de 1 a 21 .

\section{RESULTADOS E DISCUSSÃO}

A análise do conteúdo das entrevistas emergiu a categoria intitulada "a experiência da amamentação na família e o papel dos profissionais de saúde nessa prática”.

Durante as falas e orientações fornecidas, as puérperas destacaram inúmeras experiências de sua rede familiar em relação à amamentação. Trataram-se de vivências pautadas em crenças, mitos e tradições repassados na família e na comunidade de maneira intergeracional, ilustrando, assim, que a amamentação é um ato cultural, histórico e social, que ultrapassa a condição biológica.

Por meio desses relatos, pôde-se constatar que as experiências vividas pelos elementos da rede familiar e/ou da comunidade possuem forte influência na forma como as mulheres vivenciam a amamentação. Sendo assim, após o nascimento da criança, inúmeras pessoas do ciclo de convivência da mulher permitem-se opinar, relatar suas vivências e, até mesmo, influenciar diretamente nos cuidados com a puérpera e com o seu recém-nascido. ${ }^{10}$

Além disso, quando a puérpera decide amamentar ela não expressa apenas a sua decisão, mas também sua cultura, seu contexto histórico, sua motivação, suas vivências, seus conhecimentos, suas reflexões sobre vivências passadas, os significados construídos durante toda a vida, os acontecimentos durante a infância, as experiências de seus familiares e amigos, as interferências da mídia, os saberes científicos de cada época histórica e cultural, entre outros. ${ }^{11-13}$

Logo, os profissionais de saúde que prestam cuidados ao trinômio mulher-bebêfamília devem levar em consideração a cultura, a crença, os costumes, os mitos e os tabus que influenciam na prática da amamentação e que interferem na construção dessa herança 


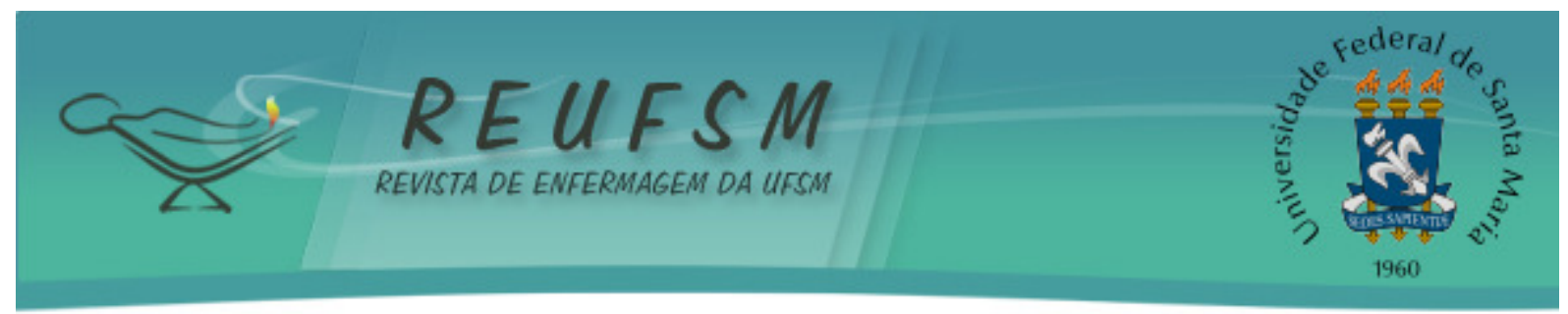

sócio-histórico-cultural, determinando os seus significados para a mulher e, por conseguinte, levando-a ou não a amamentar o seu bebê. ${ }^{7}$

Outro ponto a ser destacado refere-se ao fato de que as puérperas (E1; E4; E9; E19, por exemplo) que já haviam vivenciado a amamentação anteriormente e que tiveram experiências positivas nessa vivência foram as mesmas que seguiram amamentando e manifestaram o desejo em prosseguir com este ato. Assim, mulheres que tiveram vivências positivas, provavelmente, terão sucesso para estabelecer a amamentação e, também, serão as que poderão mantê-la por mais tempo, quando comparadas com aquelas que vivenciaram predominantemente eventos anteriores negativos. Além disso, há fortes indícios de que ter amamentado anteriormente é um fator de motivação para que a mulher deseje amamentar novamente. ${ }^{11,14}$

Nesse aspecto, destaca-se que as mulheres da rede de apoio social da puérpera, que também já aleitaram e alcançaram experiências positivas, "podem multiplicar tal consideração cultural a outras mulheres, sendo, dessa forma, apoiadoras do aleitamento materno". 11:347 Desse modo, as vivências positivas anteriores de terceiros podem representar para as mulheres um fator determinante no processo decisório do aleitamento materno, estimulando-as a tentar alcançar o mesmo objetivo. ${ }^{15}$ Portanto, percebe-se que o meio social é responsável pela maior parcela de interferências sobre a decisão de amamentar, repassando mitos, crenças e valores de geração em geração. ${ }^{12-13}$

A puérpera E21, por exemplo, relatou aspectos negativos e frustrantes em suas experiências anteriores com a amamentação. Tais experiências influenciaram substancialmente nas suas vivências atuais, repercutindo diretamente na introdução precoce de leites artificiais e outros alimentos.

Portanto, as vivências anteriores da mulher podem ou não motivar a adesão à amamentação, tendo em vista que podem ser carregadas de significados negativos, prejudicando a decisão em aleitar. ${ }^{7}$

Nesse contexto, considera-se que primíparas possam apresentar maiores dificuldades, já que não possuem qualquer experiência anterior com amamentação, ${ }^{16}$ conforme observado nas puérperas E3 e E20. Sendo assim, a primiparidade pode resultar em maiores dificuldades para amamentar nos primeiros dias após o parto, especialmente nos primeiros quatorze dias, nos quais a lactação se estabelece, representando um período de intenso aprendizado para o trinômio, no qual a mulher necessita de muito apoio e orientação. ${ }^{17-18}$

Ressalta-se, nesse ponto, que a amamentação é uma habilidade, uma arte a ser aprendida e reaprendida. Para tanto, a mulher necessita ser estimulada a aprender, assim como apoiada e ensinada. ${ }^{17,19}$ Desse modo, é necessário assistir a mulher que vivencia a amamentação, pois, muitas vezes, ela pode ter pouca ou nenhuma habilidade diante dessa prática, o que pode deixá-la mais vulnerável às dificuldades que possam surgir neste momento. Além disso, os estudos mostram que mulheres que receberam apoio e orientações nas primeiras semanas após o parto sentiram-se mais seguras e tiveram maior sucesso no processo de aleitamento. Em contrapartida, aquelas que não tiveram o mesmo suporte, que eram inexperientes ou que não tinham nenhuma experiência anterior com a amamentação, encontraram-se mais suscetíveis para o desmame precoce, demonstrando a importância de uma rede de apoio que possa dar voz à mulher e que possa compreender as suas demandas individuais frente à amamentação. ${ }^{11,19-20}$

Corroborando com esses aspectos, justifica-se a necessidade de, durante a assistência a essas mulheres, atentar-se não apenas para os aspectos biológicos, mas também para os fatores sócio-histórico-culturais que podem influenciar diretamente no ato de amamentar, possibilitando, assim, que a mulher e o recém-nascido possam realizar esta prática de forma prazerosa. ${ }^{11,19}$ 


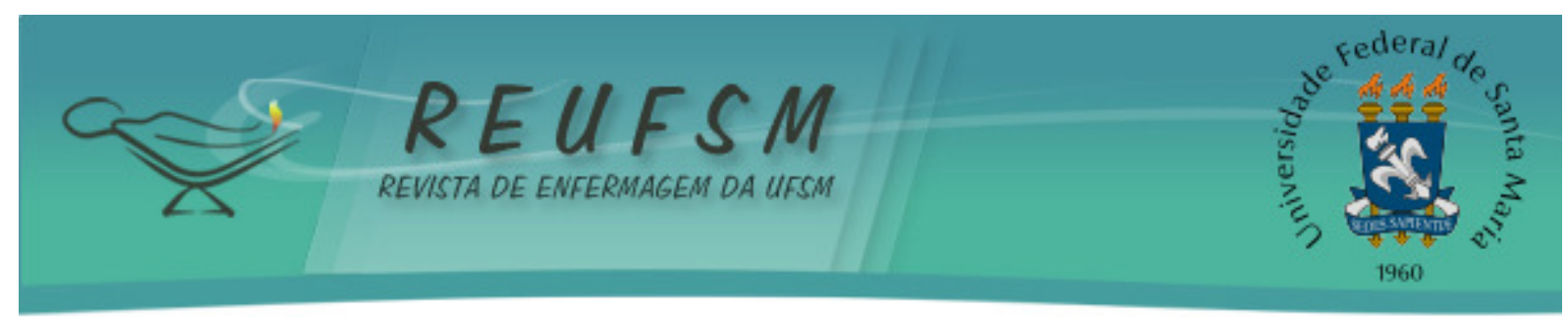

A necessidade de considerar tais fatores evidenciou-se durante as entrevistas, enquanto as participantes mencionaram as atitudes tomadas diante da ocorrência de problemas mamários. Tais atitudes foram fortemente influenciadas por familiares, amigos e profissionais de saúde, demonstrando que a amamentação não é apenas um ato pessoal, mas também social e que as influências exercidas por terceiros podem determinar comportamentos e/ou interferir nas decisões da mulher. ${ }^{6}$

Assim, é perceptível que a participação e/ou influência de pessoas significativas para a mulher no processo da amamentação, sejam elas de sua rede formal ou informal, é extremamente relevante para a mesma. Contudo, destaca-se que esses sujeitos podem interferir na amamentação tanto de forma positiva, facilitando-a, quanto de forma negativa, limitando-a..$^{5-6,11,21}$

Diante do exposto, a rede social da mulher pode auxiliá-la no ato de amamentar por meio do diálogo e compartilhamento de angústias e dúvidas; pelo incentivo e apoio fornecidos; pelo repasse de saberes e valores culturais e por meio de orientações acerca da fisiologia e dos benefícios da amamentação. ${ }^{12}$

Nas entrevistas foi possível verificar a importância do apoio recebido pelas mulheres, considerando que, entre as entrevistadas, encontravam-se trabalhadoras formais e/ou donas de casa. Mulheres que, inúmeras vezes, precisam ausentar-se de casa, que possuem diversas atividades no lar, que executam os cuidados de outros membros da família, que desenvolvem atividades na comunidade, que adoecem e também precisam de cuidados. Enfim, mulheres que precisam de suporte e apoio incondicionais e que, muitas vezes, percebem-se sozinhas e desamparadas diante de tantos papéis a serem assumidos.

Nesse contexto, a manutenção da amamentação pode mostrar-se como um desafio a ser superado. Para isso, se faz necessário o apoio familiar e de amigos, assim como os cuidados dos profissionais de saúde, sendo que estes assumem grande importância para que a amamentação se estabeleça efetivamente e tenha continuidade. ${ }^{5,17}$ Assim, a presença constante dos profissionais de saúde, companheiro, mãe, sogra, tias, irmãs, primas, amigas e vizinhas pode representar fonte de apoio à prática da amamentação. ${ }^{21}$ Em síntese, a mulher precisa de constante incentivo e suporte teórico-prático tanto dos profissionais de saúde quanto de sua família e da comunidade. ${ }^{22}$

Entretanto, é importante ressaltar que nem sempre esse apoio auxilia no processo de amamentação, pois em alguns casos, mesmo que amigos e familiares ofereçam suporte, algumas puérperas entrevistadas adotaram atitudes que resultaram na introdução de alimentos complementares à dieta da criança e acarretaram em desmame precoce.

Essas atitudes refletem hábitos, práticas e crenças enraizadas na cultura dos grupos familiares e que são repassadas entre as gerações, nas quais o desmame precoce é adotado com muita frequência. ${ }^{5-6,15,23}$ Nessa perspectiva, ao chegar no seu domicílio e deparar-se, sobretudo, com a inexperiência, dúvidas, ansiedade e impaciência, "a puérpera adota a prática do cuidado de dentro de sua família, deixando de seguir as orientações recebidas dos profissionais, nas maternidades onde tiveram seus filhos", ${ }^{15: 525}$ tornando-se suscetíveis ao desmame precoce. ${ }^{4}$

Portanto, para que os profissionais de saúde possam auxiliar efetivamente a mulher, ele precisa reconhecer as crenças e tradições que envolvem o seu contexto social, de modo a identificar práticas que desfavorecem a amamentação.

Sobre esse aspecto, verifica-se que os profissionais envolvidos com a saúde da mulher durante o período gravídico-puerperal possuem pouco conhecimento sobre as práticas populares que envolvem a amamentação, o que os impossibilita de discutir, desmitificar e esclarecer certas práticas culturais com a comunidade. Na ausência dessas discussões, depreende-se que muitas práticas identificadas durante as entrevistas, como, por exemplo, a utilização de fórmulas, chupetas, água e chás e a introdução precoce de 


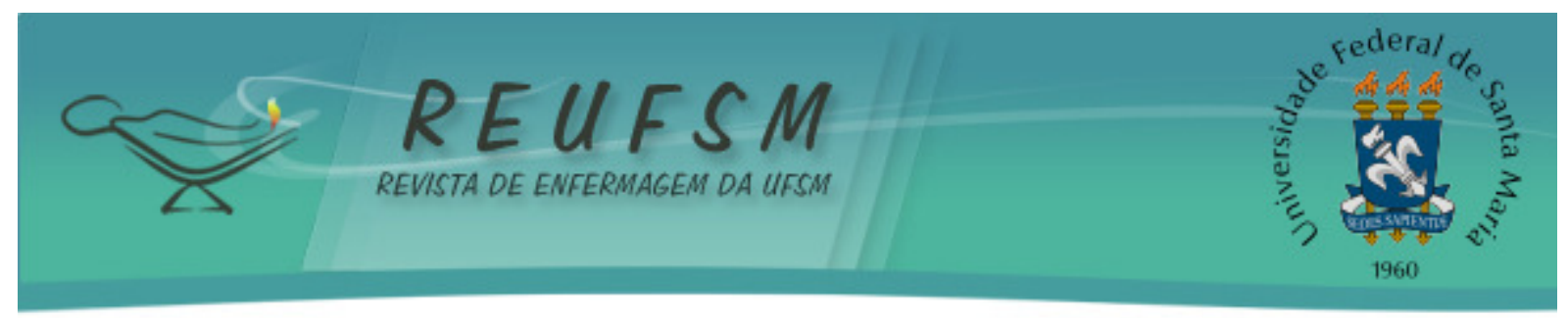

alimentos continuarão perpetuando-se ao longo das gerações, desfavorecendo a amamentação. Portanto, esses são assuntos emergentes que devem ser trabalhados durante as ações de pré-natal e puerpério, de modo a estimular comportamentos, atitudes e práticas saudáveis na população.

Desse modo, a mulher poderá empoderar-se para decidir sobre a forma de alimentar seu filho. Para tanto, é preciso que a mesma acredite na sua capacidade de produzir leite ao seu bebê, além de receber orientações sobre como estimular e manter a produção do leite, entre outras orientações que se façam necessárias. Acredita-se que o conhecimento materno pode influenciar diretamente na concretização do ato de amamentar e, assim, ao investir neste "poder decisório, ao revés das influências e opiniões equivocadas de familiares significativos, ou de profissionais despreparados ao apoio adequado, a amamentação pode ser coroada de êxito". ${ }^{21: 33}$

Além de trazer essas discussões para as ações que envolvem o período gravídicopuerperal, também se faz necessário levá-las para outros contextos, tornando a amamentação antes de um ato social, também uma prática protegida pela sociedade.

Um desses contextos é o próprio ambiente escolar, no qual a amamentação pode ser trabalhada de forma a ser entendida como uma prática histórica e cultural. Assim, o desenvolvimento de estratégias educativas e participativas junto às crianças e adolescentes poderia dar início às discussões em torno da amamentação como uma das muitas possibilidades na vida da mulher e não apenas como a única e obrigatória, construindo nesses jovens o entendimento de que a mulher que não deseja amamentar não deve ser culpabilizada por essa decisão. ${ }^{24}$

Ao mesmo tempo, muitas das crenças encontradas nesse estudo poderiam ser discutidas nesses espaços, mostrando que a amamentação é um ato social, capaz de mudar conforme a época, os costumes, as culturas e os valores transmitidos de geração para geração. Tais ações permitiriam, também, a ressignificação da amamentação para os sujeitos. $^{12}$

Com isso, destaca-se que o espaço do ambiente escolar foi levantado como uma possibilidade de discussão sobre a temática, devido ao fato de que estudos vêm mostrando que as vivências de mulheres no período da infância, durante o processo de socialização primária, quando estas mulheres presenciaram suas mães, tias ou outras mulheres amamentando, também podem determinar a forma como a amamentação será vivida por elas, seja como um ato de prazer ou como um fardo. ${ }^{23}$

Outro contexto que merece destaque é a mídia, a qual, por muitas vezes, veicula a amamentação apenas como uma forma instintiva e natural de alimentar a criança, indiferente do desejo da mulher, trazendo um discurso velado que culpabiliza e responsabiliza a mesma diante da ocorrência de desmame precoce. ${ }^{4}$ Assim, há de se repensar formas de discutir a amamentação na sociedade, de maneira a não reproduzir essas ideologias, levando as discussões sobre a temática aos meios de comunicação, bem como na vida intrafamiliar e na sociedade, de modo a resultar em maior número de crianças amamentadas exclusivamente ao seio materno, até pelo menos, os seis meses de vida. ${ }^{\hat{1}}$

Por fim, ressalta-se que independente da existência de fatores externos que estimulem ou limitem a amamentação, de indivíduos que possam apoiar ou desencorajar a mulher, bem como o desejo ou desinteresse da mesma em amamentar; de uma maneira geral, a amamentação pode se apresentar como um momento de realização plena da feminilidade para algumas mulheres. ${ }^{23}$

Logo, embora muitas mulheres manifestem um desejo inicial de não amamentar, estas, muitas vezes, modificam sua concepção diante da influência, das cobranças, dos comentários, dos julgamentos e da pressão exercida pelo meio social. ${ }^{22} \mathrm{Em}$ contraponto, 


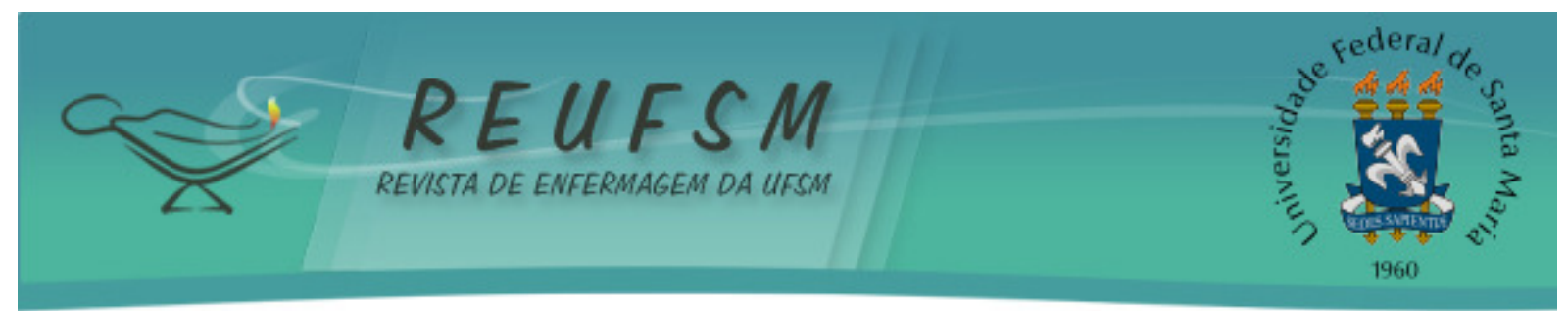

pensa-se que essa concepção não é modificada, já que, muitas vezes, as mulheres acabam cedendo devido à grande pressão sofrida por terceiros.

Esse aspecto foi observado em algumas entrevistas quando as puérperas demonstraram ter dado continuidade na amamentação devido à vontade de terceiros e não por seu próprio interesse. Com isso, estas vêm adotando práticas passadas de mães para filhas/noras, principalmente, no que se refere às condutas adotadas frente aos problemas encontrados na amamentação.

\section{CONSIDERAÇÕES FINAIS}

De acordo com os achados desta pesquisa, foi possível verificar que para desempenhar o papel de apoiadores e incentivadores da amamentação, os profissionais de saúde necessitam se aproximar da rede familiar da puérpera, a fim de conhecer os seus saberes e experiências, e a forma como esses influenciam esta prática.

Dessa forma, os mesmos poderão compartilhar conhecimentos e práticas, como também implementarão ações que possam promover, proteger e apoiar o aleitamento materno, auxiliando na construção de uma rede de suporte e apoio à mulher e sua família, na qual possa haver um somatório de saberes técnicos e populares que permita à mulher, ao recém-nascido e sua família superarem os obstáculos e vivenciarem satisfatoriamente a amamentação.

Depreende-se, a partir desse estudo, a necessidade de estratégias que contemplem a rede familiar, uma vez que é nesse contexto que são repassados mitos e crenças ligados à amamentação, que podem influenciar na decisão da mulher em amamentar. Logo, mostra-se necessário sensibilizar e empoderar a família quanto às questões ligadas à amamentação como forma de efetivar esta prática.

Com isso, apontam-se algumas possibilidades de aproximação entre profissionalpuérpera-família, como os grupos de gestantes, nos quais é possível a troca de conhecimentos, assim como o esclarecimento de dúvidas e a difusão de cuidados a serem adotados durante a gravidez e o puerpério. Outra estratégia são as visitas domiciliares que permitem uma maior aproximação com a realidade de cada mulher, bem como a identificação das práticas que vêm sendo repassadas dentro do contexto familiar e a aplicação de suporte condizente com a realidade de cada mulher e família.

Sugere-se que estratégias como estas sejam trabalhadas desde o processo de formação dos profissionais, já que em alguns espaços de aprendizado, a temática amamentação ainda é vista sem grande importância. Faz-se necessário, portanto, o desenvolvimento de novas alternativas de cuidado, que permitam aos profissionais um papel mais decisivo na prática da amamentação, atuando de forma mais sensível e efetiva à realidade das mulheres.

\section{REFERÊNCIAS}

1. Silveira CL, Budó MLD, Silva FM, Durgante VL, Wünsch S, Simon BS, et al. Cuidadora de familiar com doença crônica incapacitante: percepções, motivações e repercussões. Rev Enferm UFSM [Internet]. 2012 [acesso em 2013 ago 20];2(1):67-78. Disponível em: http://cascavel.ufsm.br/revistas/ojs-2.2.2/index.php/reufsm/article/view/3828.

2. Silva TP, Leite JL, Santos NLP, Silva ÍR, Mendonça ACA, Santos MJC, et al. Cuidados de enfermagem a criança com câncer: uma revisão integrativa da literatura. Rev Enferm UFSM [Internet]. 2013 [acesso em 2013 ago 20];3(1):68-78. Disponível em: http://cascavel.ufsm.br/revistas/ojs-2.2.2/index.php/reufsm/article/view/6918. 


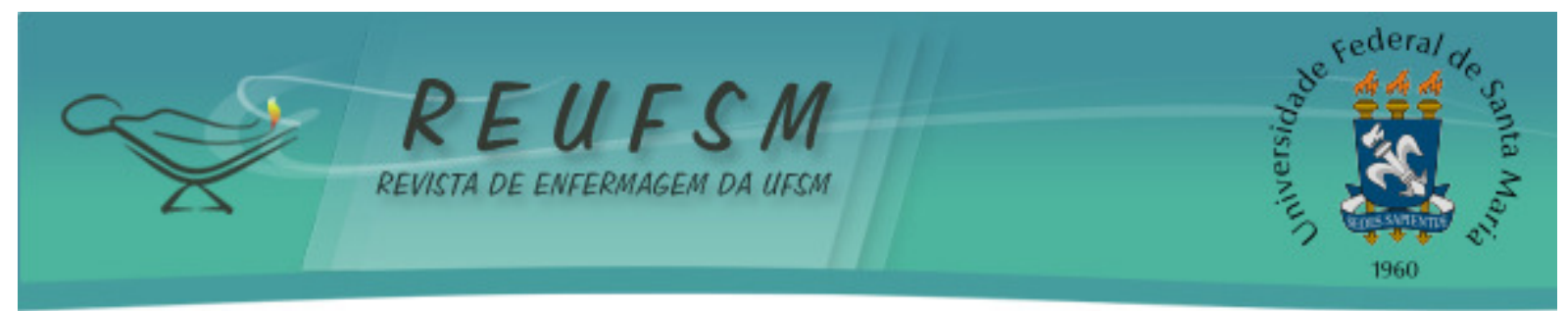

3. Brasil. Ministério da Saúde. Saúde da criança: nutrição infantil: aleitamento materno e alimentação complementar. Brasília (DF): Editora do Ministério da Saúde; 2009.

4. Parizotto J, Zorzi NT. Aleitamento materno: fatores que levam ao desmame precoce no município de Passo Fundo, RS. Mundo Saúde. 2008;32(4):466-74.

5. Teixeira MA, Nitschke RG, Silva LWS. A prática da amamentação no cotidiano familiar um contexto integeracional: influência das mulheres-avós. Rev Kairós [Internet]. 2011 [acesso em 2013 ago 12];14(3):205-21. Disponível em: http://revistas.pucsp.br/index.php/kairos/article/view/6501.

6. Barreira SMC, Machado MFAS. Amamentação: compreendendo a influência familiar. Acta Sci Health Sci [Internet]. 2004; [acesso em 2013 ago 11];26(1):11-20. Disponível em: http://periodicos.uem.br/ojs/index.php/ActaSciHealthSci/article/view/1606.

7. Araújo RMA, Almeida JAG. Aleitamento materno: o desafio de compreender a vivência. Rev Nutr. 2007;20(4):431-8.

8. Minayo MCS. O desafio do conhecimento: pesquisa qualitativa em saúde. $10^{a}$ ed. São Paulo: Hucitec; 2007.

9. Brasil. Ministério da Saúde. Conselho Nacional de Saúde. Resolução CNS n 196, de 10 de outubro de 1996. Diretrizes e normas regulamentadoras de pesquisas envolvendo seres humanos. Brasília (DF): Conselho Nacional de Saúde; 1996.

10. Zanin LC, Schacker LC. Avós maternas: incentivadoras da amamentação? Rev Conhecimento Online [Internet]. 2010 [acesso em 2013 ago 11];1:1-13. Disponível em: http://www.feevale.br/site/files/documentos/pdf/35211.pdf.

11. Junges CF, Ressel LB, Budó MLD, Padoin SMM, Hoffmann IC, Sehnem GD. Percepções de puérperas quanto aos fatores que influenciam o aleitamento materno. Rev Gaúcha Enferm [Internet]. 2010 [acesso em 2013 ago 11];31(2):343-50. Disponível em: http://seer.ufrgs.br/RevistaGauchadeEnfermagem/article/view/10041.

12. Marques ES, Cotta RMM, Magalhães KA, Sant'Ana LFR, Gomes AP, Batista RS. A influência da rede social da nutriz no aleitamento materno: o papel estratégico dos familiares e dos profissionais de saúde. Ciênc Saúde Colet. 2010;15(1):1391-400.

13. Frota MA, Costa FL, Soares SD, Sousa Filho OA, Albuquerque CM, Casimiro CF. Fatores que interferem no aleitamento materno. Rev RENE [Internet]. 2009 [acesso em 2013 ago 13];10(3):617. Disponível em: http://www.revistarene.ufc.br/revista/index.php/revista/article/view/53.

14. Dodt RCM, Oriá MOB, Pinheiro AKB, Almeida PC, Ximenes LB. Perfil epidemiológico das puérperas assistidas em um alojamento conjunto. Rev Enferm UERJ. 2010;18(3):345-51.

15. Zorzi NT, Bonilha ALL. Práticas utilizadas pelas puérperas nos problemas mamários. Rev Bras Enferm. 2006;59(4):521-6.

16. Gatti L. Maternal perceptions of insuficiente milk supply in breastfeeding. J Nurs Scholarsh. 2008;40(4):355-63.

17. Tamez RN. Atuação de enfermagem. In: Carvalho MR, Tavares LAM. Amamentação: bases científicas. $3^{\mathrm{a}}$ ed. Rio de Janeiro: Guanabara Koogan; 2010.

18. Baptista GH, Andrade AHHKG, Giolo SR. Fatores associados à duração do aleitamento materno em crianças de famílias de baixa renda da região sul da cidade de Curitiba, Paraná, Brasil. Cad Saúde Pública. 2009;25(3):594-604. 


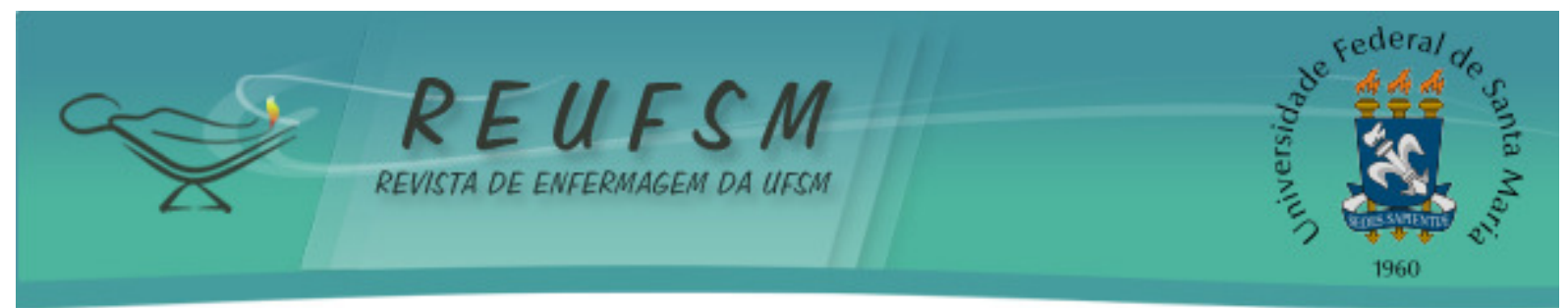

19. Teixeira MA, Nitschke RG. Modelo de cuidar em enfermagem junto às mulheres-avós e sua família no cotidiano do processo de amamentação. Texto \& Contexto Enferm. 2008;17(1):183-91.

20. Rocha NB, Garbin AJI, Garbin CAS, Moimaz SAS. 0 ato de amamentar: um estudo qualitativo. Physis. 2010;20(4):1293-305.

21. Alves BA, Cursi J, Labegalini MPC, Higarashi IH, Bercini LO. Mães com aleitamento materno exclusivo em centro de educação infantil no local de trabalho. Rev RENE [Internet]. 2009 [acesso em 2013 ago 11];10(3):27-36. Disponível em: http://www.revistarene.ufc.br/revista/index.php/revista/article/view/512.

22. Silva VF, Pessoa CGO. Fatores determinantes do aleitamento materno exclusivo em uma cidade de Minas Gerais. Rev Enferm Integrada [Internet]. 2012 [acesso em 2013 ago 15];5(1):86779. Disponível em: http://www.unilestemg.br/enfermagemintegrada/artigo/v5/01-fatoresdeterminantes-do-aleitamento-materno-exclusivo-em-uma-cidade-de-minas-gerais.pdf.

23. Machado MMT, Bosi MLM. Compreendendo a prática do aleitamento exclusivo: um estudo junto a lactantes usuárias da Rede de Serviços em Fortaleza, Ceará, Brasil. Rev Bras Saúde Matern Infant. 2008;8(2):187-96.

24. Marques ES, Cotta RMM, Priore SE. Mitos e crenças sobre o aleitamento materno. Ciênc Saúde Colet. 2011;16(5):2461-8.

Data de recebimento: 08/09/2013

Data de aceite: 14/02/2014

Contato com autor responsável: Lisie Alende Prates

Endereço postal: Programa de Pós-Graduação em Enfermagem - Centro de Ciências da Saúde - Universidade Federal de Santa Maria - Avenida Roraima n ${ }^{\circ} 1000$, Prédio 26 - Cidade Universitária - CEP: 97105-900, Santa Maria, RS, Brasil.

E-mail: lisiealende@hotmail.com 